Original Article

\title{
SIMULTANEOUS DETERMINATION OF METFORMIN, LINAGLIPTIN IN JENTADUETO AND METFORMIN, SAXAGLIPTIN IN KOMBIGLYZE BY LC-MS METHOD
}

\author{
P. B. N. PRASAD ${ }^{a^{*},}$ K. SATYANARAYANA ${ }^{b}$, G. KRISHNA MOHANc
}

${ }^{*}$ CDSCO, Zonal Office, Hyderabad, CDSCO BHAVAN, Beside T. B. and Demonstration Centre, S. R. Nagar, Hyderabad 500038, Telangana, ${ }^{\text {R }}$ and D NATCO Research Center, B-11, Sanath Nagar Rd, Czech Colony, Cooperative Industrial Estate, Sanath Nagar, Hyderabad, Telangana 500018, 'Department of Pharmaceutical Sciences, Jawaharlal Nehru Technological University, Kukatpally, Hyderabad, Telangana 500085 Email: pulijala_bnprasad@yahoo.com

Received: 17 Oct 2017 Revised and Accepted: 25 Jan 2018

\section{ABSTRACT}

Objective: The objective of the present investigation was to develop a novel, simple and economic method for the determination of metformin (MET), linagliptin (LIN) and saxagliptin (SAX) in jentadueto and kombiglyze sample by employing the liquid chromatography and mass spectrometric method for estimation in bulk and pharmaceutical dosage form in presence of degradation products.

Methods: The chromatographic separation was achieved by using the mobile phase composition of methanol and ammonium acetate buffer $\mathrm{pH} 4.5$ $(85: 15 \% \mathrm{v} / \mathrm{v})$ on the Hypurity advance C-18 column at a flow rate of $0.5 \mathrm{ml} / \mathrm{min}$. Ion signals m/z "130.10/70.10, 473.10/420.40 and $316.30 / 180.20$ " for metformin, linagliptin and saxagliptin respectively measured in positive ion mode. The detailed validation of the method was performed as per ICH guidelines.

Results: The results of all validation parameters found within acceptance limits. The linearity of the drugs was found to be in the concentration range of $50-5000 \mathrm{ng} / \mathrm{ml}$ for all the drugs. Accuracy of the drugs was found to be from $94-102 \%$ and precision was found 4.67\% RSD for all three drugs. The validated method was employed for the determination of drugs in the formulation and also determined the drugs in the presence of degradation products under stress conditions.

Conclusion: The method was developed and validated as per guidelines. Hence, this method can be used for the simultaneous determination of metformin, linagliptin and metformin, saxagliptin in bulk and combined dosage forms.

Keywords: Linagliptin, LC-MS, Method development, Metformin, Saxagliptin, Validation

(C) 2018 The Authors. Published by Innovare Academic Sciences Pvt Ltd. This is an open access article under the CC BY license (http://creativecommons.org/licenses/by/4.0/) DOI: http://dx.doi.org/10.22159/ijpps.2018v10i3.23187

\section{INTRODUCTION}

Biguanide class drug metformin hydrochloride (N,N-dimethyl imido carbonamide diamide), an oral anti-diabetic drug is used as a firstline choice for the treatment of type 2 diabetes, particularly in overweight or obese people and those with normal kidney function. Metformin reduces hyperglycemia, primarily through its suppressive action on hepatic gluconeogenesis and also by increasing glucose transport across the cell membrane in skeletal muscle [1-3].

Linagliptin, 8-[(3R)-3-aminopiperidin-1-yl]-7-(but-2-yn-1-yl)-3-methyl1-[(4-ethylquinazolin-2-yl) methyl]-3,7-dihydro-1H-purine-2,6dione] is a novel dipeptidyl peptidase- 4 inhibitor representing a new therapeutic approach by stimulating glucose-dependent insulin release and reduction of glucagon levels. It acts through inhibiting the inactivation of incretins particularly glucagon-like peptide- 1 and gastric inhibitory polypeptide $[4,5]$.

Saxagliptin is a potent, selective, reversible dipeptidyl peptidase 4 (DPP4) inhibitor specifically designed for extended inhibition of the DPP4 enzyme. Saxagliptin is recently approved for treatment of type-II diabetes mellitus [6]. DPP-4 inhibitors represent a new therapeutic approach to the treatment of type-II diabetes that functions to stimulate glucose-dependent insulin release and reduce glucagon levels. This is done through inhibition of incretins inactivation, particularly glucagon-like peptide-1 and gastric inhibitory polypeptide, thereby improving glycemic control [7].

A few analytical methods were reported for the determination of MET, LIN and SAX in individual/combined dosage forms [8-23]. The present investigation was to develop a novel, simple and economic method for the determination of MET, LIN and SAX in jentadueto and Kombiglyze sample by employing the liquid chromatography and mass spectrometric method for estimation in bulk and pharmaceutical dosage form. Further, it is applied for studying of stress degradation of the drugs.

\section{MATERIALS AND METHODS}

\section{Instrumentation}

The instruments employed in the present study are as follows; HPLCAgilent 1200 Series, AB Sciex API-3200 with Analyst Software 1.4.2, Agilent technologies, Santa Clara, USA, centrifuge apparatus-Multifuge, Thermofisher scientific, Mumbai, India, sonicator-Sharp Analytical, Hyderabad, India, rotary shaker-Vibramax, Germany, analytical balance-Metler Toledo, Mumbai, India, Pipettes-Thermo Electron, UK.

\section{Chemicals}

Metformin hydrochloride (MET, 99.35\%), linagliptin (LIN, 98.26\%) and saxagliptin (SAX, 99.59\%) are from Clearsynth Company, Mumbai, India. ammonium acetate, formic acid and methanol are purchased from Merck Ltd, Mumbai, India.

\section{Stock and working solution preparation}

Preparation of MET standard stock solution: $6.240 \mathrm{mg}$ of MET has weighed accurately and transferred to $5 \mathrm{ml}$ volumetric flask, then added methanol to dissolve and made up to mark with methanol to get the $1 \mathrm{mg} / \mathrm{ml}$ solution of MET.

Preparation of LIN standard stock solution: $5.124 \mathrm{mg}$ of LIN was weighed accurately and transferred to $5 \mathrm{ml}$ volumetric flask, then added methanol to dissolve and made up to mark with methanol. The resultant solution was $1 \mathrm{mg} / \mathrm{ml}$. a solution of LIN.

Preparation of SAX standard stock solution: $5.214 \mathrm{mg}$ of SAX was weighed accurately and transferred to $5 \mathrm{ml}$ volumetric flask, then 
added methanol to dissolve and made up to mark with methanol. The resultant solution was $1 \mathrm{mg} / \mathrm{ml}$ solution of SAX.

Preparation of Mobile phase: Weighed and transferred $0.7708 \mathrm{~g}$ of ammonium acetate dissolved it in $1000 \mathrm{ml}$ of water and adjusted the $\mathrm{pH}$ of the solution to 4.5 with formic acid. $150 \mathrm{ml}$ of above solution was diluted with $850 \mathrm{ml}$ of methanol, mixed and sonicated. This mixture was used as mobile phase.

\section{Sample preparations}

Sample preparation for metformin in jentadueto: Ten tablets were weighed and the coats were removed by carefully rubbing with a clean tissue wetted with methanol, $5 \mathrm{ml}$ of methanol was added to an accurately weighed amount of the finely powdered jentadueto tablets equivalent to $500 \mathrm{mg}$ of metformin and $2.5 \mathrm{mg}$ of linagliptin, sonicated for $25 \mathrm{~min}$ and then made up to $10 \mathrm{ml}$ with methanol. The resulting solutions were found to be $250 \mu \mathrm{g} / \mathrm{ml}$ of linagliptin and $50,000 \mu \mathrm{g} / \mathrm{ml}$ of metformin.

To $0.050 \mathrm{ml}$ of sample, $950.00 \mathrm{ml}$ of the mobile phase was added and vortexed. Then the sample was transferred to autosampler vial, loaded the vials into autosampler and injected $10 \mu \mathrm{l}$ of sample into LC/MS/MS system. The same procedure was followed for the preparation of metformin samples of Kombiglyze sample.
Sample preparation for linagliptin in jentadueto: Ten tablets of jentadueto was weighed and then finely powdered. An accurately weighed portion of the powder equivalent to $2000 \mathrm{mg}$ of metformin and $10 \mathrm{mg}$ of linagliptin was transferred to $100 \mathrm{ml}$ volumetric flask and $50 \mathrm{ml}$ methanol was added and sonicated for $25 \mathrm{~min}$. Then the volume was made up to $100 \mathrm{ml}$ with methanol and was filtered. $0.05 \mathrm{ml}$ of jentadueto sample was diluted with $150.0 \mathrm{ml}$ of mobile phase and vortexed. Then the sample was transferred to autosampler vial, loaded the vials into autosampler and injected $10 \mu \mathrm{l}$ of sample into LC/MS/MS system.

Sample preparation for saxagliptin in kombiglyze: $0.050 \mathrm{ml}$ of kombigylze sample was diluted with $150.0 \mathrm{ml}$ of mobile phase and vortexed. Then the sample was transferred to autosampler vial, loaded the vials into autosampler and injected $10 \mu \mathrm{l}$ of sample into LC/MS/MS system.

Instrument parameters and characterization of production using mass spectrometry

One micromole of MET, LIN and SAX solutions were separately infused into the mass spectrometer at a flow rate of $10 \mu \mathrm{l} / \mathrm{min}$, to characterize the productions of each compound. The precursor ions $\left[\mathrm{M}^{+} \mathrm{H}\right]^{+}$and the pattern of fragmentation were monitored using the positive ion mode. The major peaks observed in the MS/MS scan were used to quantify MET, LIN and SAX. The chromatographic conditions and multiple reaction monitoring (MRM) settings of the instrument were presented in [table 1].

Table 1: Chromatographic and mass conditions of the instrument (LC-MS)

\begin{tabular}{|c|c|c|c|}
\hline \multicolumn{2}{|c|}{ Chromatographic conditions } & \multicolumn{2}{|l|}{ MRM conditions** } \\
\hline In source & Turbo ion spray & Curtain gas (CUR) & 25.0 PSI \\
\hline Column & Hypurity advance C-18 & Collision gas (CAD) & 5.0 PSI \\
\hline Mobile phase & Methanol: ammonium acetate buffer $\mathrm{pH} 4.5(85: 15 \% \mathrm{v} / \mathrm{v})$ & Temperature (TEM) & $550.0^{\circ} \mathrm{C}$ \\
\hline Flow rate & $0.5 \mathrm{ml} / \mathrm{min}$ & Ion spray voltage & $5500 \mathrm{~V}$ \\
\hline Volume of injection & $10 \mu \mathrm{l}$ & Gas- 1 and Gas-2 & 40.0 PSI \\
\hline Run time & $3 \mathrm{~min}$ & Entrance potential & $10.0 \mathrm{~V}$ \\
\hline Detection ions & & Collision cell exit potential & $\begin{array}{l}\text { MET-2.0 V } \\
\text { LIN-5.0 V } \\
\text { SAX-2.0 V }\end{array}$ \\
\hline Metformin & 130.10* amu (parent) 70.10* amu (product) & Declustering potential (DP) & $\begin{array}{l}\text { MET-25.0 V } \\
\text { LIN-55.0 V } \\
\text { SAX-40.0 V }\end{array}$ \\
\hline Linagliptin & $473.10^{*}$ amu (parent) 420.40* amu (product) & Collision energy & MET-35.0 V \\
\hline Saxagliptin & $316.30^{*}$ amu (parent) $180.20^{*}$ amu (product) & & $\begin{array}{l}\text { LIN-33.0 V } \\
\text { SAX-33.0 V }\end{array}$ \\
\hline
\end{tabular}

Note: * parameters may change by 0.5 units. ${ }^{* *}$ these parameters may vary from one instrument to another instrument due to their mass calibration parameters.

\section{Method validation}

The validation parameters like specificity, linearity, sensitivity, and accuracy, precision were done according to the ICH guidelines [24] and also referred few publications on method development and validation $[25,26]$. Selectivity is studied by comparing the chromatograms obtained from placebo sample with the chromatogram obtained from tablets. Calibration standards are prepared by spiking required volume of working standard of MET, LIN and SAX solution in different $10 \mathrm{ml}$ volumetric flasks and volume made up with methanol to yield concentration range of 50$5000 \mathrm{ng} / \mathrm{ml}$ of drugs. The resultant peak areas of drugs were measured. The linearity of the method was determined by plotting the peak area $(y)$ of drugs (MET, LIN and SAX) against normal concentration $(x)$ of drugs, respectively.

The lower limit of quantification (LLOQ) for drugs was defined as the lowest concentration giving a signal-to-noise ratio of at least 10 fold, acceptable accuracy (80-120\%), and precision (within 20\%); this was verified by the analysis of 10 replicates. Intra-and inter-day accuracy and precision of this method were determined at three different concentration levels on three different days, and on each day, three replicates were analyzed. The accuracy and precision were expressed as percentage accuracy and relative standard deviation (R. SD, \%) respectively, and calculated using following equation (1) and (2).

$$
\begin{gathered}
\text { Accuracy }(\%)=\frac{\text { Mean observed concentration }}{\text { Nominal concentration }} \times 100 \\
\% \mathrm{RSD}=\frac{\text { Standard deviation }}{\text { Mean }} \times 100
\end{gathered}
$$

\section{RESULTS}

\section{Method development}

The drugs are in polar nature, so the reverse-phase chromatography was adopted using hydrophobic Hypurity advance, C-18 column $(5 \mu$, $100 \times 4.6 \mathrm{~mm}$ ) at a $0.5 \mathrm{ml} / \mathrm{min}$ flow rate than evaluated various compositions of mobile phases to obtain better resolution and symmetric peak shapes of analyte as well as suitable retention time. Buffers like ammonium acetate, ammonium formate and acetic acid in various strengths were tried along with methanol as organic solvent. These buffers gave sharp peak shape, but poor response. Finally, the mobile phase consisting of $10 \mathrm{mmol}$ ammonium acetate buffer: methanol (15:85) gave a sharp peak shape and good response.

The mass spectrometric detection of drugs (MET, LIN and SAX) were investigated by ESI positive ion mode. In the positive ion mode, MET gave protonated molecular ions, $\left[\mathrm{M}^{+} \mathrm{H}\right]^{+}$, as the major species. The fragmentation patterns of the protonated molecular ions were evaluated by increasing the collision energy. The greatest intensities 
were observed at 130.10/71.10 amu for MET, 473.40/420.40 amu for LIN and at 136.30/180.20 amu for SAX, respectively. The mass parameters were optimized by observing the maximal response of the productions. The transition of $130.10 \rightarrow 71.10 \mathrm{amu}, 473.40 \rightarrow 420.40$ amu and $136.30 \rightarrow 180.20$ amu were used for detection of MET, LIN and SAX respectively. After optimization of the above conditions, the method was validated according to the ICH guidelines. The chromatograms of MET, LIN and SAX were shown in [fig. 1. a, 1. b, 1. c].

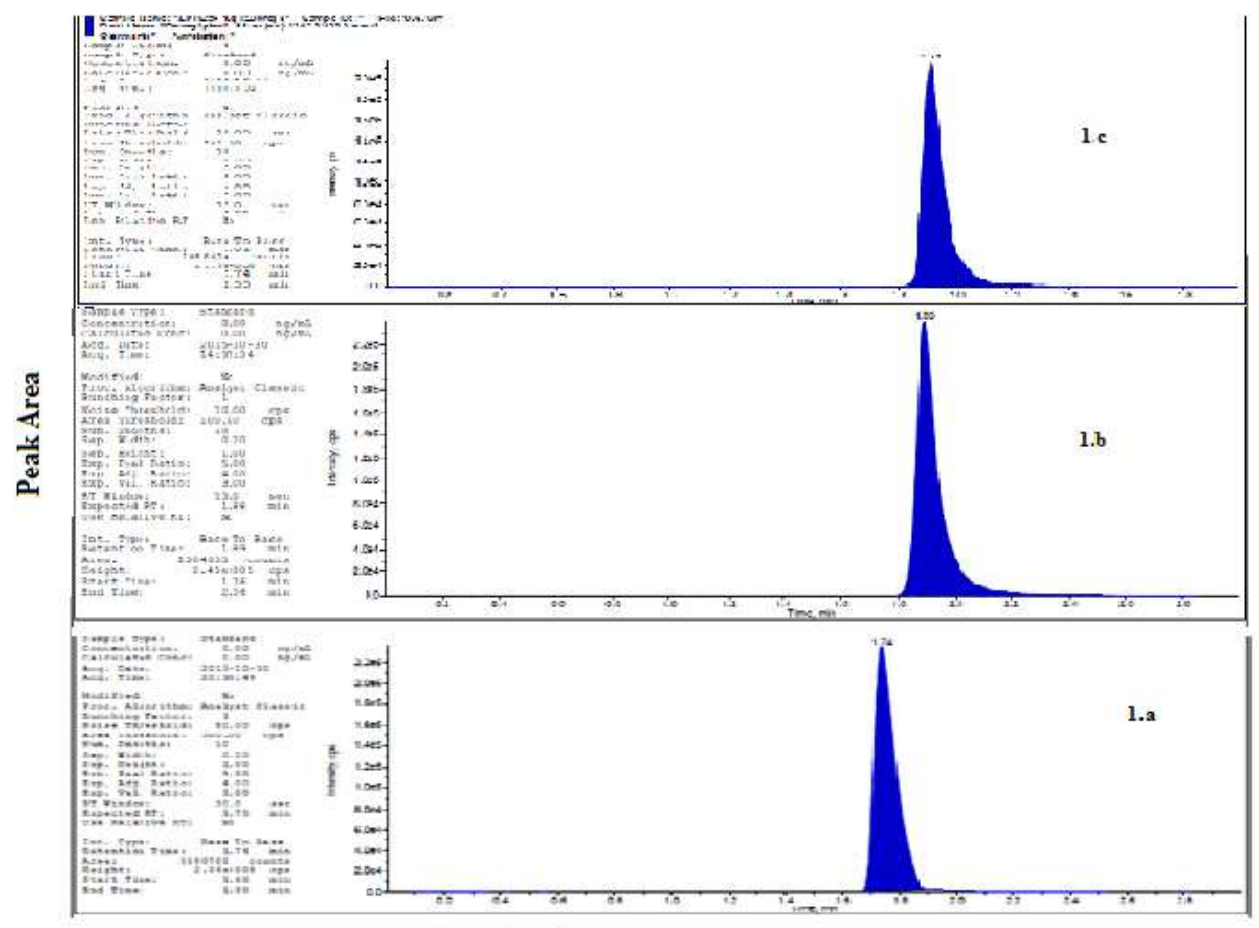

Time in min

Fig. 1: Standard chromatogram of MET (1a), LIN (1b) and SAX (1c)

\section{Method validation}

Selectivity: The selectivity of the present method is established by checking the blank sample and observed the chromatogram. There is no interference found in retention times of MET, SAX and LIN in the blanks concludes the selectivity of the method.

Linearity: The linearity of this method was evaluated by linear regression analysis, using the least square method. The drug concentrations were linear in a range of $50-5000 \mathrm{ng} / \mathrm{ml}$.
Calibration standards were prepared by spiking required volume of working standard $(10000 \mathrm{ng} / \mathrm{ml})$ solution along with internal standard into different $10 \mathrm{ml}$ volumetric flasks and volume made up with methanol to yield concentrations 50,100, 300, 1000, 2000 and $5000 \mathrm{ng} / \mathrm{ml}$ of drugs. The resultant peak area of the drug was measured. A calibration curve was plotted between the peak area of the drug against the concentration of the drug.

The [fig. 2] represents the linearity graph, regression coefficient $\left(r^{2}\right)$ including the slope and $y$-intercept.

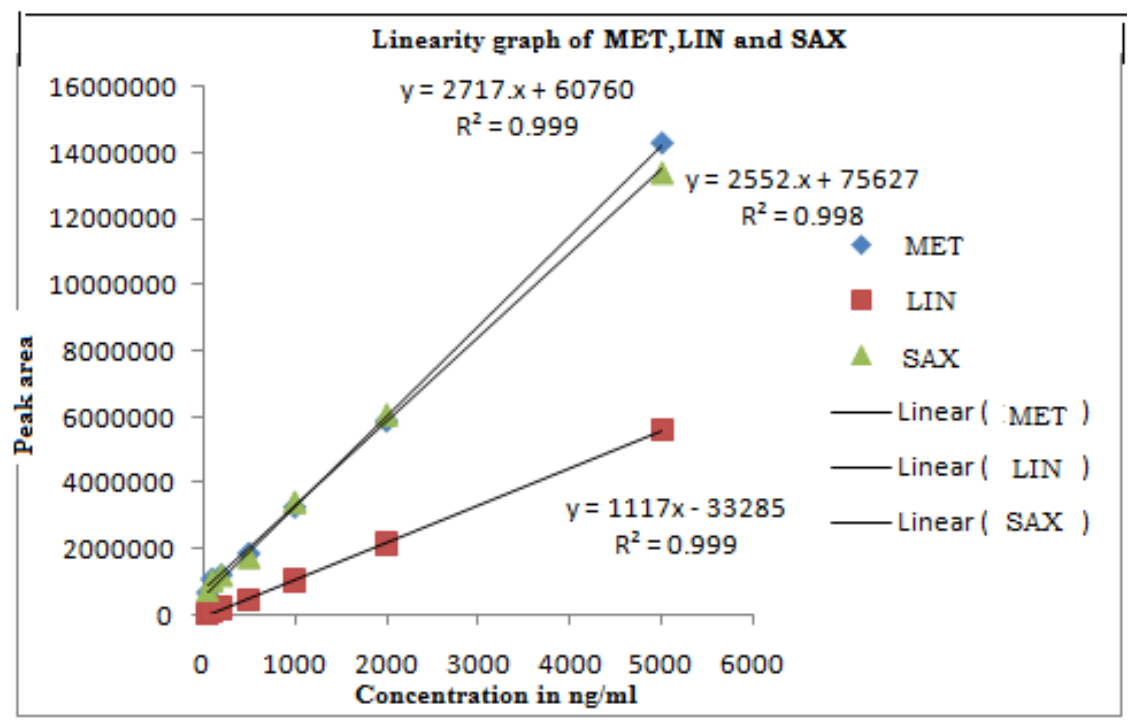

Fig. 2: Linearity graph of MET, LIN and SAX, n=6 
Sensitivity: The lower limit of quantitation (LLOQ) was found to be $50 \mathrm{ng} / \mathrm{ml}$. The percent accuracy of LLOQ was $109.68 \%$, and precision denoted by $\%$ RSD was $4.73 \%$.

Intra-day and Inter-day Precision and Accuracy: The intra-and interday: precision and accuracy of this assay were determined by analyzing replicates of $\mathrm{QC}$ samples at three concentrations on three different days. The coefficients of variation for the intra-and interday precisions were $<4.67 \%$. The intra-and inter-day accuracies were $94.50-102.50 \%$. The low levels of coefficients of variation, i.e.: $2.51 \%-4.67 \%$ [table 2] indicate the method is accurate and precise. All these criteria were acceptable and follow ICH.

Table 2: Intra-day and inter-day accuracy and precision of MET, LIN and SAX

\begin{tabular}{|c|c|c|c|c|c|c|c|}
\hline & Standard & MET & & LIN & & SAX & \\
\hline & & Avg. conc. & Accuracy & Avg. conc. & $\begin{array}{l}\text { Accuracy mean } \pm \text { SD, } \% \\
\text { RSD }\end{array}$ & $\begin{array}{l}\text { Avg. } \\
\text { conc. }\end{array}$ & $\begin{array}{l}\text { Accuracy } \\
\text { mean } \pm \text { SD, \% RSD }\end{array}$ \\
\hline Intra-day & 150.35 & 142.09 & $94.5 \pm 2.38,2.51$ & 143.63 & $95.5 \pm 0.70,0.73$ & 142.1 & $94.5 \pm 2.38,2.51$ \\
\hline \multirow[t]{2}{*}{$(n=6)$} & 1500 & 1501.55 & $102.42 \pm 3.64,3.56$ & 1500.97 & $100.06 \pm 0.08,0.08$ & 1501.5 & $102.4 \pm 3.64,3.56$ \\
\hline & 4000 & 4106.55 & $102.42 \pm 3.64,3.56$ & 4000.93 & $100 \pm 0.03,0.03$ & 4106.49 & $102.4 \pm 3.64,3.56$ \\
\hline Inter-day & 150.35 & 142.77 & $96.96 \pm 3.98,4.10$ & 143.96 & $95.53 \pm 1.26,4.10$ & 142.69 & $96.96 \pm 3.98,4.10$ \\
\hline \multirow{2}{*}{$(n=18)$} & 4009.15 & 1507.29 & $102.50 \pm 4.78,4.67$ & 1501.87 & $99.82 \pm 0.48,0.48$ & 1507.3 & $102.50 \pm 4.78,4.67$ \\
\hline & 4000 & 4109.29 & $102.50 \pm 4.78,4.67$ & 4000.39 & $99.91 \pm 0.15,0.15$ & 4109.4 & $102.50 \pm 4.78,4.66$ \\
\hline
\end{tabular}

Note: Actual concentrations of drugs mentioned in $\mathrm{ng} / \mathrm{ml}$. Values are expressed in mean $\pm \mathrm{SD}$

Ruggedness: Ruggedness was studied along with precision and accuracy of batches where the effect of column change and analyst change were observed. The observed value for column variation and results obtained for precision and accuracy were within the acceptance criteria (i.e. there were no changes in the retention time, recovery and precision of the drug) according to US-FDA and ICH.

\section{Analysis of formulation of jentadueto and kombiglyze}

The samples were studied for various stress conditions like acid, base, hydrogen peroxide and photolytic conditions and the drug quantities were measured after standard and sample jentadueto and kombiglyze samples individually injected. Metformin standard solution and mixture of linagliptin and saxagliptin standard solution separately injected in six replicates.

Along with the samples (jentadueto and kombiglyze) the standard solution samples were interspersed in a run and all the results are tabulated in [table 3] and [table 4]. The chromatograms of drugs, both the sample for jentadueto and kombiglyze were shown in [fig. 3 (a) and 3 (b), and $4 \mathrm{a}$ and $4 \mathrm{~b}$ ] respectively.

Table 3: Degradation data of drugs in jentadueto sample

\begin{tabular}{lll}
\hline Sample & MET (100ng/ml) & LIN (1000 ng/ml) $^{*}$ \\
\hline Standard & $1199057 \pm 31741$ & $1256839 \pm 65739$ \\
$0.1 \mathrm{~N} \mathrm{HCl}$ & $3167698 \pm 96408$ & $26158 \pm 1166$ \\
$1 \mathrm{~N} \mathrm{HCl}$ & $2931780 \pm 100795$ & $11637 \pm 1365$ \\
$0.1 \mathrm{~N} \mathrm{NaOH}$ & $2324546 \pm 96459$ & $25797 \pm 2432$ \\
$1 \mathrm{~N} \mathrm{NaOH}$ & $1149570 \pm 39839$ & $11944 \pm 754$ \\
$\mathrm{H}_{2} \mathrm{O}_{2}$ & $3585314 \pm 168909$ & $43640 \pm 1024$ \\
Photolytic & $3871644 \pm 149582$ & $0.00 \pm 0.0$ \\
\hline
\end{tabular}

*Values expressed in mean $\pm \mathrm{SD}, \mathrm{n}=3$

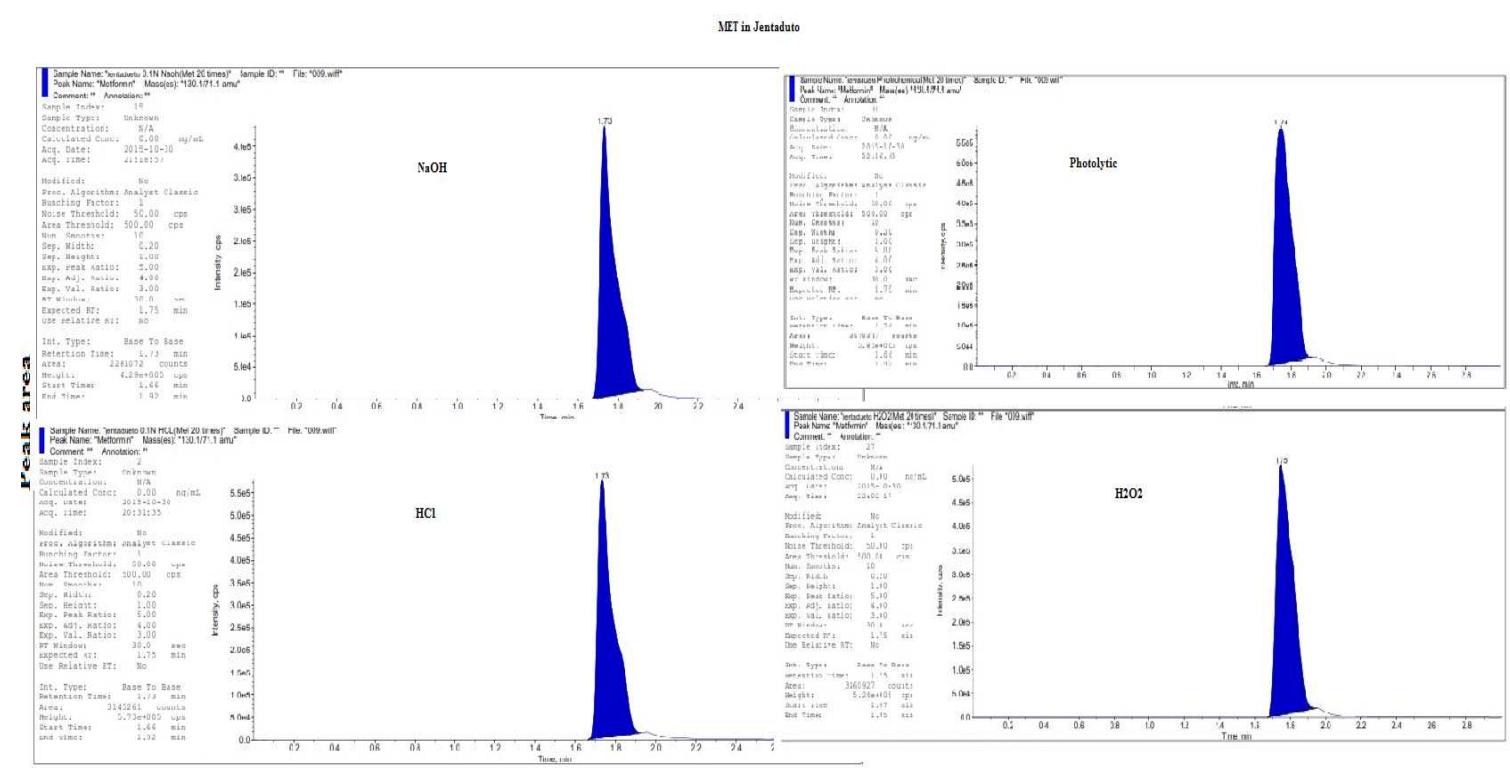

Time in Min

Fig. 3(a) 
Prasad et al.
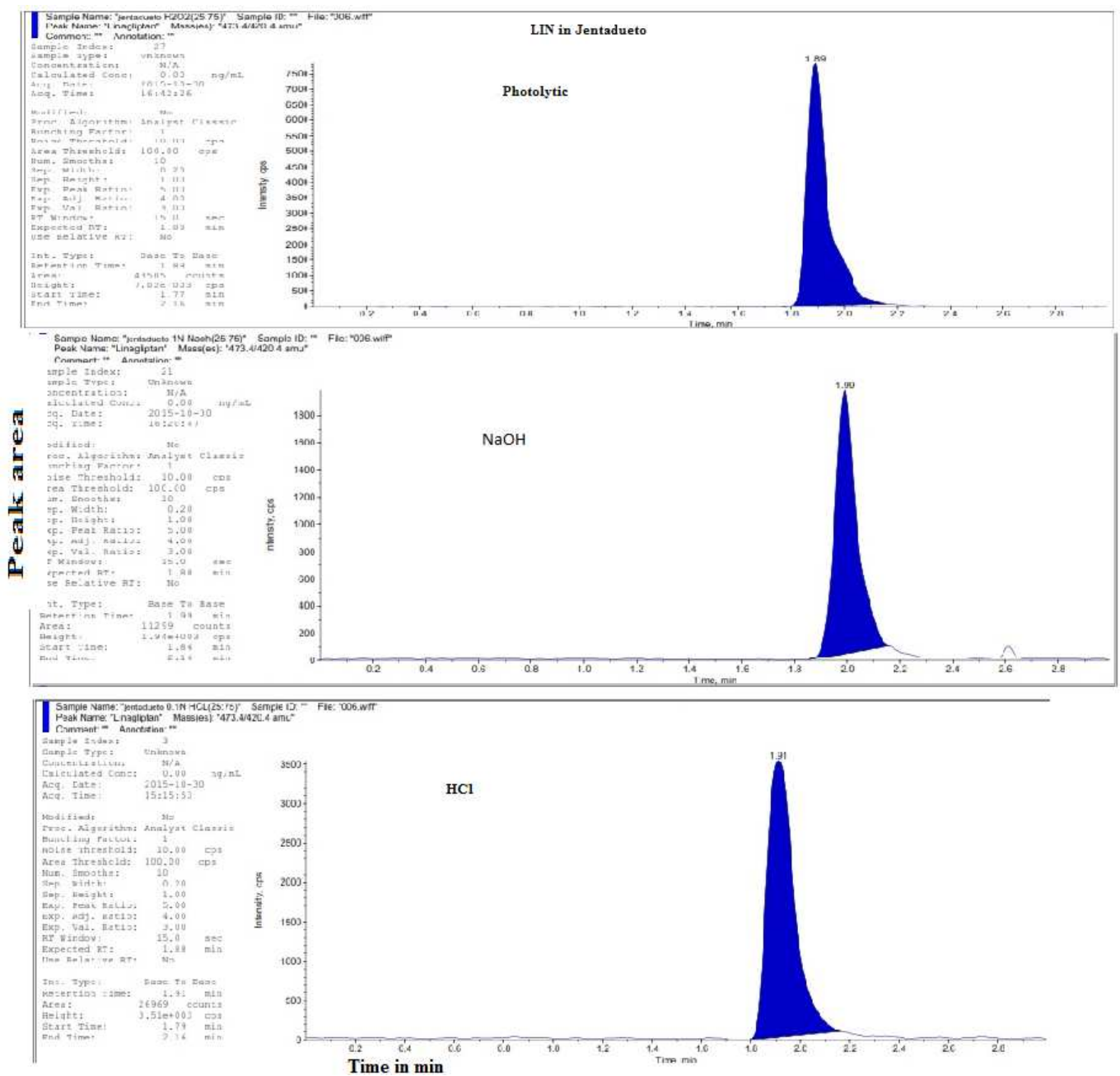

Fig. 3(b)

Fig. 3a: Chromatograms of MET in jentadueto sample and fig. 3. b. Chromatograms of LIN in jentadueto sample under stress conditions
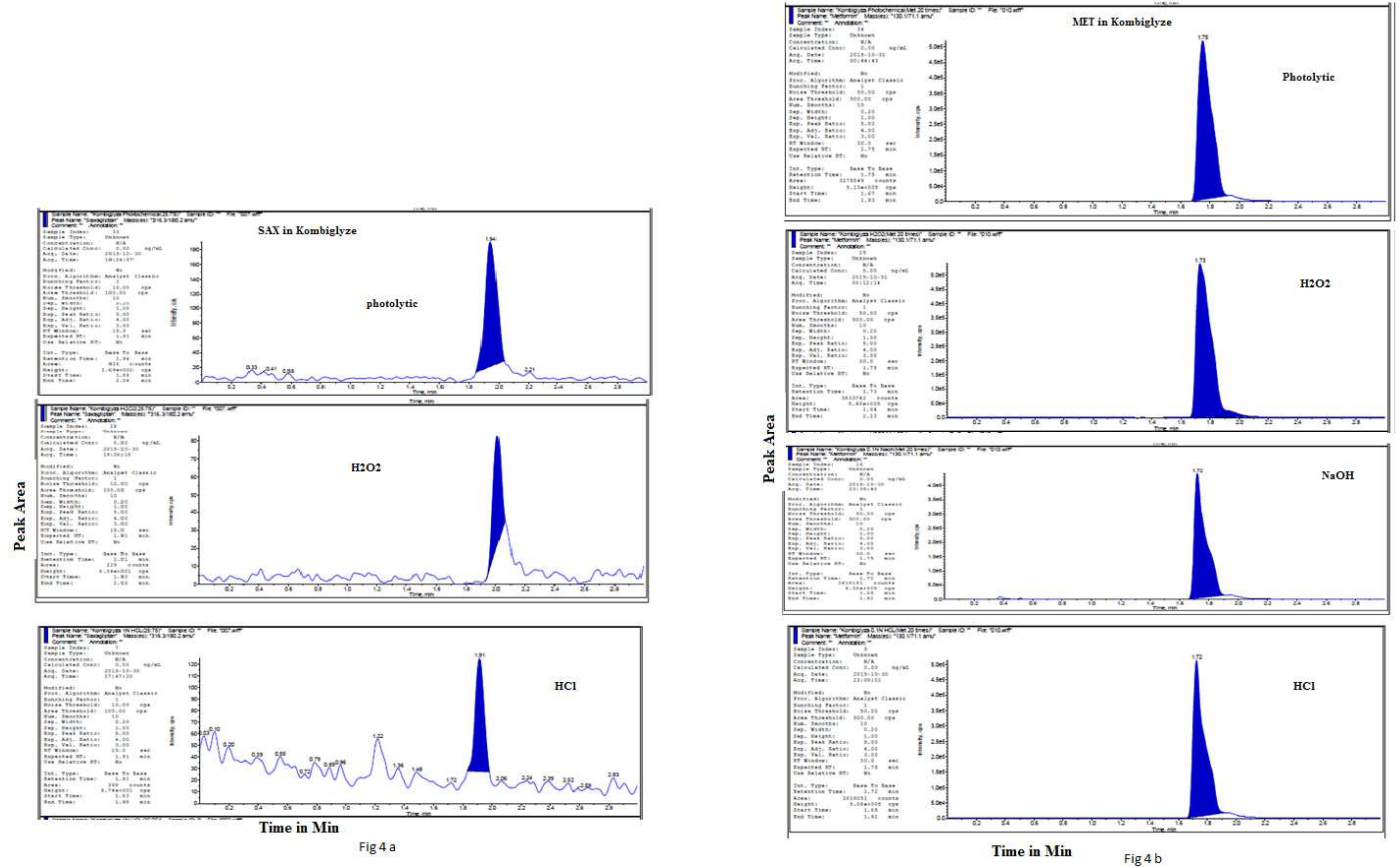

Fig. 4: Chromatograms of MET (4a) and SAX (4b) in kombiglyze sample under stress conditions 
Table 4: Degradation data of drugs in kombiglyze sample

\begin{tabular}{lll}
\hline Sample & MET (100ng/ml) & SAX $^{*}(\mathbf{2 0 0} \mathbf{n g} / \mathbf{m l})^{*}$ \\
\hline Standard & $1199057 \pm 31741$ & $1087995 \pm 23445$ \\
$0.1 \mathrm{~N} \mathrm{HCl}$ & $2844320 \pm 80666$ & $582.40 \pm 105$ \\
$1 \mathrm{~N} \mathrm{HCl}$ & $1872539 \pm 106140$ & $175.80 \pm 174$ \\
$0.1 \mathrm{~N} \mathrm{NaOH}$ & $2200686 \pm 154669$ & $0.00 \pm 0.00$ \\
$1 \mathrm{~N} \mathrm{NaOH}$ & $1054260 \pm 29420$ & $0.00 \pm 0.00$ \\
$\mathrm{H}_{2} \mathrm{O}_{2}$ & $3589928 \pm 194918$ & $45.80 \pm 102.41$ \\
Photolytic & $3430214 \pm 223323$ & $905.60 \pm 73.21$ \\
\hline
\end{tabular}

*Values expressed in mean $\pm \mathrm{SD}, \mathrm{n}=3$

\section{DISCUSSION}

The chromatographic method was optimized by changing various parameters, such as $\mathrm{pH}$ of the mobile phase, organic modifier and buffer used in the mobile phase. Under the presently prescribed conditions, the recoveries were found to be $94.5 \%-102.50 \%$ for MET, $95.5 \%-100.06 \%$ for LIN and $94.5 \%-102.5 \%$ for SAX. This indicates that commonly used excipients in jentadueto and kombiglyze samples were not interfering in the proposed method. Hence, this method is very useful for determination of MET, LIN and SAX in pharmaceutical dosage forms. It was also found that the differences of less than $5.0 \%$ for three intra-and inter-day data reflect the precision of the method. The observation of $\%$ C. $\mathrm{V}$ less than 5.0 for both intra-and inter-day measurements also indicates a high degree of precision. In this study, the developed chromatographic method the linearity range of $50-5000 \mathrm{ng} / \mathrm{ml}$ for three drugs will cover all the concentrations of drugs in a sample of jentadueto and kombiglyze. The LOQ of the method was $50 \mathrm{ng} / \mathrm{ml}$ for all three drugs, it is a more sensitive method compared to reported method Asiya et al.2013 [28]. Owing to the high sensitivity the method was used to detect the drugs in different stress degradation conditions i.e. acidic, alkaline, and photolytic.

The stress studies were conducted for LIN and MET combination by HPLC method. In acid and alkali hydrolysis of both MET and LIN were degraded by increasing the strength of acid and alkali and similarly degradation was also observed with peroxide. Further studies in photolytic degradation, MET was quantifiable significantly whereas LIN was found to be quantifiable but very low. LIN was completely degraded in the photolytic condition and detectability in either the drug or its degradants was not possible and hence no quantification of linagliptin by LCMS was observed. SAX was completely degraded in the alkaline and peroxide solutions but partially degraded in acidic and photolytic conditions. The saxagliptin (SAX) or its degradants were not detectable. Hence no quantification of saxagliptin was attempted.

In the present study, Jentadueto was subjected to stress conditions like acid, base, peroxide, and photolytic degradation. This lead to there was no interference of degradants with the drug peaks. The degradation studies of jentadueto reveal that the developed method was stability indicating hence, this method can easily and conveniently adopted for routine quality control analysis of metformin and linagliptin in pure and its pharmaceutical dosage forms like jentadueto, This study was in agreement with Kavitha et al.,. 2013 (27) HPLC method.

Further, in LC-MS analysis Stress-induced studies performed under different conditions employed like acid, base, peroxide, and photolytic. In each degradation study for both metformin and linagliptin it was observed that metformin was found to be stable in acidic media as compared alkaline media the degradation was more in alkali whereas, there are no changes in metformin content in peroxide and photolytic degradation. In case of linagliptin degradation was increased with acidity, similarly with alkali. In case of peroxide-induced degradation of linagliptin was found to be significant, but in case of photolytic degradation there was not a single fragment eluted in LC-MS method.

Saxagliptin was completely degraded in the alkaline and peroxide solutions but partially degraded in acidic and photolytic conditions. The saxagliptin or its degradants were not detectable. Hence, no quantification of saxagliptin was attempted. It was found that the degradation of saxagliptin was found to be very highly significant $(\mathrm{P}<0.001)$ as mentioned from the [table 4].

Linagliptin was completely degraded in the photolytic condition and detectability in either the drug or its degradants was not possible and hence no quantification of linagliptin by LCMS was attempted. The stress studies were conducted for linagliptin and metformin combination by HPLC method. In acid and alkali hydrolysis of both metformin and linagliptin were degraded by increasing the strength of acid and alkali and similarly degradation was also observed with peroxide. Further studies in photolytic degradation, metformin were quantifiable significantly, whereas linagliptin was found to be quantifiable but very low. The degradation was highly significant $(\mathrm{P}<0.001)$ as mentioned in [table 3]. It may also be due to the concentration of linagliptin employed for the study was very low in case of the LCMS.

\section{CONCLUSION}

The present developed method indicates more sensitive than earlier methods reported in the literature. Jentadueto sample stress degradation studies indicate linagliptin was found to be sensitive against acidic, alkali, peroxide media but in photolytic studies totally degraded and not a single fragment detectable in LC-MS. In the case of kombiglyze sample, stress studies indicate saxagliptin was found to be highly sensitive against alkali media not a single fragment of saxagliptin was detectable. Further, saxagliptin was found to be quantifiable in other forced degradation studies like acidic, photolytic and peroxide. The method is highly useful for for quantification of metformin, linagliptin and saxagliptin in their combinations like Jentadueto and Kombiglyze. The method is novel and specific and can be applied as an alternative to HPLC as the analytical method is supported by forced degradation studies and the comparative data indicates the method is robust and specific

\section{ACKNOWLEDGEMENT}

The facility provided for authors to work on HPLC in Central Drugs Testing Laboratory, CDSCO, Zonal office, Hyderabad, CDSCO BHAVAN, S. R. Nagar, Hyderabad and LCMS method at VIMTA LABS, Hyderabad is highly acknowledged.

Authors' contribution: P. B. N. Prasad has carried the experimental work, Dr. K. Satynarayana has gave the idea of extending the HPLC studies to LC-MS and Dr. G. Krishnamohan has done the comparative study and interpretation.

\section{AUTHORS CONTRIBUTIONS}

All the author have contributed equally

\section{CONFLICT OF INTERESTS}

Declared none

\section{REFERENCES}

1. Campbell DB, Lavielle R, Nathan C. The mode of action and clinical pharmacology of gliclazide: a review. Diabetes Res Clin Pract 1991;14:21-36.

2. Moses R. Fixed combination of repaglinide and metformin in the management of type 2 diabetes. Diabetes Metab Syndr Obes: Targets Ther 2009;2:101-9.

3. Tripathi KD. Essential of medical pharmacology. 5th Ed. Jaypee Brothers Medical publisher, New Delhi; 2004. p. 248-9. 
4. Kirby M, Yu DM, O'Connor S, Gorrell MD. Inhibitor selectivity in the clinical application of dipeptidyl peptidase-4 inhibition. Clin Sci 2009;118:31-41.

5. Salsali A, Pratley RE. Does addition of sitagliptin to metformin monotherapy improve glycemic control in patients with type 2 diabetes mellitus? Nat Clin Pract Endocrinol Metab 2007;3:450-1.

6. Augeri DJ, Robl JA, Betebenner DA, Magnin DR, Khanna A, Robertson JG, et al. Discovery and preclinical profile of saxagliptin (BMS-477118): a highly potent, long-acting, orally active dipeptidyl peptidase IV inhibitor for the treatment of type 2 diabetes. J Med Chem 2005;48:5025-37.

7. Kulasa K, Edelman S. Saxagliptin: the evidence for its place in the treatment of type 2 diabetes mellitus. Core Evidence 2010;5:23-37.

8. Parag P, Imran M, Bairagi V, Ahire Y. Development and validation of stability indicating UV spectrophotometric method for the estimation of sitagliptin phosphate in bulk and tablet dosage form. J Pharm Res 2011;4(Suppl 3):871-3.

9. Khan, Agrawal YP, Sabarwal N, Jain A, Gupta AK. Simultaneous estimation of metformin and sitagliptin in tablet dosage form. Asian J Biochem Pharma Res 2011;1(Suppl 2):352-8.

10. Ramzia El-Bagary, Ehab EF, Bassam AM. Spectrofluorometric and Spectrophotometric methods for the determination of sitagliptin in binary mixture with metformin and ternary mixture with metformin and sitagliptin alkaline degradation product. Int J Biomed Sci 2011;7(Suppl 1):62-9.

11. Ravi PP, Sastry BS, Rajendra PY, Appala RN. Simultaneous estimation of metformin $\mathrm{HCl}$ and sitagliptin phosphate in tablet dosage forms by RP-HPLC. Res J Pharm Tech 2011;4(Suppl 4):646-9.

12. Shyamala M, Mohideen S, Satyanarayana T, Narasimha R, Suresh K, Swetha K. Validated RP-HPLC for simultaneous estimation of sitagliptin phosphate and metformin hydrochloride in tablet dosage form. Am J Pharm Tech Res 2011;1(Suppl 2):93-101.

13. Zeng $\mathrm{W}, \mathrm{Xu}$ Y, Constanzer M, Woolf EJ. Determination of sitagliptin in human plasma using protein precipitation and tandem mass spectrometry. JChromatogr Biomed Appl 2010;878(Suppl 21):1817-23.

14. Zeng W, Musson DG, Fisher AL, Chen L, Schwartz MS, Woolf EJ, et al. Determination of sitagliptin in human urine and hemodialysate using turbulent flow online extraction and tandem mass spectrometry. J Pharm Biomed Anal 2008;46(Suppl 3):534-42.

15. Nirogi R, Kandikere V, Mudigonda K, Komarneni P, Aleti R, Boggavarapu R. Sensitive liquid chromatography-tandem mass spectrometry method for the quantification of sitagliptin, a DPP-4 inhibitor, in human plasma using liquid-liquid extraction. Biomed Chromatography 2008;22(Suppl 2):214-22.

16. Ucakturk, Ebru. Development of a gas chromatography-mass spectrometry method for the analysis of sitagliptin in human urine. J Pharm Biomed Anal 2013;74:71-6.
17. Haak T. Combination of linagliptin and metformin for the treatment of patients with type 2 diabetes. Clin Med Insights Endocrinol Diabetes 2015;8:1-6.

18. Madhukar A, Prince, Vijay Kumar R, Sanjeev Y, Jagadeeshwar K, Raghupratap. Simple and sensitive analytical method development and validation of metformin hydrochloride by RP-HPLC. Int J Pharm Pharm Sci 2011;3(Suppl 3):117-20.

19. Nazar Mustafa Mansoory, Anurekha Jain. Simultaneous estimation of metformin hydrochloride, pioglitazone hydrochloride and gliclazide by a validated RP-HPLC method in the solid dosage form. Int J Pharm Sci 2012;4(Suppl 5):72-6.

20. Bonde S, Bhadane RP, Avinash Gaikwad, Deepak Katale, Sumit Gavali S Narendiran. A simple and sensitive method for determination of Metformin and Sitagliptin in human plasma using liquid chromatography and tandem mass spectrometry. Int J Pharm Pharm Sci 2013;5(Suppl3):463-70.

21. Anushaakula N, Prajwala, Sandhya M, Uma Maheswara Rao. Development and validation of an RP-HPLC method for simultaneous estimation of metformin hydrochloride and gliclazide in bulk and combined dosage form. Int J Pharm Sci 2013;5(Suppl 4):511-7.

22. Janardhan Swamy A, Harinadha Baba K. Analytical method development and method validation for the simultaneous estimation of metformin $\mathrm{HCl}$ and linagliptin in bulk and tablet dosage form by RP-HPLC method. Int J Pharm 2013;3(Suppl 3):594-600.

23. James D Terish Bino, Kannappan, Sasi Jith, Suresh Kumar. Simultaneous estimation and method development for 1 carnitine and metformin in human plasma using the liquid chromatography-mass spectrometer. Asian J Pharm Clin Res 2015;8:185-91.

24. ICH Tripartite Guideline. Validation of analytical procedures: text and methodology. International Conference on Harmonization, European Commission, Japan and USA; 2005.

25. Radhika Shah, Ragin Shah. Stability indicating RP-HPLC method for simultaneous estimation of dosulepin hydrochloride and methylcobalamin in tablet dosage form. Int J Appl Pharm 2017;9:69-75.

26. Sridhar Siddiraju, Rayala Kavitha, Muvvala Sudhakar. Reverse phase high-performance liquid chromatography method development and validation for the simultaneous estimation of gatifloxacin and flurbiprofen in the pharmaceutical dosage form. Asian J Pharm Clin Res 2015;8:242-2.

27. Kavitha KY, Geetha G, Hariprasad R, Kaviarasu M, Venkatnarayanan R. Development and validation of stability indicating an RP-HPLC method for the simultaneous estimation of linagliptin and metformin in the pure and pharmaceutical dosage form. J Chem Pharm Res 2013;5:230-5.

28. Asiya Begum, Shilpa K, A Ajitha, V Uma Maheshwar Rao. Development and validation of stability indicating a Rp-HPLC method for saxagliptin and metformin in tablet dosage form. Int J Pharm 2014;4:271-9. 